\title{
A Support Group for Inpatient Abused Adolescents
}

MARILYN M. STANISZ, BSN, RN

This article describes a support group of two years' duration for physically, sexually, and emotionally abused adolescents in an inpatient unit at the University of Michigan Child and Adolescent Psychiatric Hospital. Group characteristics, group dynamics, and emotional reactions of the adolescents are discussed. This experience suggests that a support group does not necessarily need a homogeneous membership, as the literature often indicates, to be successful.

$\mathrm{G}$ ROUP THERAPY AS A TREATMENT modality for sexually abused adolescents is discussed increasingly in the literature. The homogeneous membership of these groups often is emphasized and deemed desirable (Hazzard, King, \& Webb, 1986; Knittle \& Tuana, 1980; Lubell \& Soong, 1982). This article describes an experience with a heterogeneous support group for abused adolescents. Group characteristics, group dynamics, and emotional reactions of the adolescents are discussed.

\section{Group Characteristics}

A support group for abused adolescents was begun in the inpatient unit at the University of Michigan Child and Adolescent Psychiatric Hospital in 1987. The group coleaders are a female clinical nurse and a male resident physician. The nurse is an ongoing co-leader while the physician is co-leader for the length of his rotation (6 months) and then is replaced by a new resident. The adolescents are from 12 to 17 years in age, and the group comprises both males and females. Patients join the group shortly after admission to the hospital or as soon as a history of abuse becomes evident. They remain in the group until discharge from the hospital (average, 6-8 weeks).

The abuse experience of the individual group members is varied and includes sexual, physical, and emotional abuse.

Reprint requests: Marilyn Marie Stanisz, BSN, RN, Clinical Nurse III, Child Adolescent Psychiatric Hospital, University of Michigan Hospitals, 1500 E. Medical Center Drive, Ann Arbor, MI 48109-0706.

Accepted for publication August 23, 1989.
From the Child Adolescent Psychiatric Hospital, University of Michigan, Ann Arbor, Michigan

In some cases, the abuse has been repetitive; in others it was a single occurrence. The perpetrator is either a family member, a friend, or a stranger. Placement of the adolescent in the group is determined largely by the adolescent's own perception of the event(s) as abusive and his or her ability to work productively in a group. Severely disturbed adolescents may not be included in the group until their functioning improves. The size of the group varies from two to eight members. The overall inpatient unit capacity is fourteen. The group meets for 45 minutes once per week.

\section{Group Dynamics}

\section{The Safety Theme}

The group is called the safe group. The group is described by the adolescents as a safe place to express feelings and share experiences. The theme of safety and keeping oneself safe is continually stressed. On rare occasions, the adolescents have become verbally abusive and/or threatening to each other in the group. This behavior is identified as abusive within the group and clearly labeled as unacceptable. On two occasions, adolescents were banned from the group until they could agree to nonabusive conduct in the group. Each of these adolescents missed only one session each and following the confrontation, began, for the first time, to work productively in the group. These confrontations led to important work on the tendency for some of the adolescents to minimize their abuse and, in the process, to minimize their own worth. The adolescents were also able to look at repetitive patterns of abuse, and several members discussed abusing their pets and expressed fears that they might become abusive parents in the future (Bass \& Davis, 1988; Straus, Gelles, \& Steinmetz, 1980). 
Additionally, the safety theme has allowed for increased flexibility in the focus of the group. One group of adolescents, for example, for several sessions focused not on past abuse, but on their ability to keep themselves safe in the present. Each of them identified patterns of placing themselves in unsafe situations and inviting further abuse. They also explored the influence of alcohol and other drugs on their decision making and judgment.

The leaders have also found it important to allow the group to focus on issues other than abuse that they find pressing at the time. Quite frequently these other issues are interpersonal happenings in the hospital milieu which again can be viewed in terms of safety. For example, group members have discussed their fears either of an aggressive patient or of a severely disturbed, unpredictable patient. This discussion inevitably leads to discussion of past fears and feelings of helplessness in their own abusive experiences.

\section{Membership Changes and Group Dynamics}

As noted earlier, the group membership changes frequently. The adolescents not only adjust to the open-ended nature of the group, but actually use it to their advantage. They have developed a tradition of assigning the most senior member of the group a position of particular importance and leadership. This senior member introduces new members to the group and explains the purpose and rules of the group. The senior member also stresses the importance of confidentiality. Surprisingly, even some of the most withdrawn, reluctant members have become actively involved in the group upon becoming the senior member. The senior member often will give a personal account of abuse for the 2 nd, $3 \mathrm{rd}$, or even 4th time, allowing and encouraging newer members to speak about the "unspeakable." This repetition also seems to be helpful to the senior member who often experiences more feelings with each account of the abuse.

\section{Group Size}

Another variable that has an impact upon the adolescents is the size of the group. As stated earlier, the number of group members ranges from two to eight. The norm seems to be three to five members. Yalom (1985) suggests that "the ideal size of an interactional therapy group is approximately seven or eight members, with an acceptable range of five to ten members" (p. 283). The leaders initially were concerned, when the group size dropped to two adolescents, that the teens would feel inhibited and become reluctant to talk. In some instances this indeed happered. But the opposite reaction also was observed. Some teens who had formerly been less verbal and more withdrawn in a larger group, suddenly became very active participants in the smaller group.

\section{Heterogeneity and Gender Dynamics}

A review of the literature reveals that many of the groups being conducted have a rather homogeneous membership (Hazzard et al., 1986; Knittle \& Tuana, 1980; Lubell \& Soong, 1982). As noted earlier, this group is heterogeneous in nature, including both males and females with varying histories of abuse. Despite these differences, members typically form a cohesive group based on the commonalities they share. For instance, the majority of adolescents have been abused by adult males. Consequently, there is sometimes an initial reluctance on the part of some group members to trust and share with the male co-leader. In these situations, it has been helpful for the female co-leader to take a more active role in leading and encouraging discussion, and for the male co-leader to concentrate more on supportive and empathic responses. Gradually, distrustful members build trust with the male coleader, and what began as a disadvantage clearly becomes an advantage. These members are able to experience caring and concern from a trustworthy male. They also have the valuable experience of learning how to evaluate whether or not they can trust a new person. This issue is generalized in the group to include discussion of how to evaluate the safeness of new people and situations that members might encounter in the future.

Generally, the combination of male and female adolescents in the group is not problematic. Again, there sometimes is reluctance to talk in front of the opposite sex. This seems to be true particularly for young girls who were raped or abused by boys closer to their own age. With support and time, the girls overcome their reluctance and even have been pleased to find themselves trusting and accepting the support of the adolescent males in the group.

On one occasion, an adolescent boy was very resistant to revealing his abusive experience to the group. He had been sexually abused at the age of twelve by an uncle who had been babysitting him. This boy maintained an angry and withholding position through a number of group sessions. When he eventually disclosed his abuse, he also was able to share his fear that the female group members would see him as "weak" and a "sissy" because he was unable to stop the abuse by his uncle. At this point he was able to discuss the paralyzing fear that he had experienced and to realize that he had truly believed his uncle might kill him. When group members were empathic in their responses, this young boy, for the first time, entertained the idea that maybe he was not to blame and had done the best that he could in the situation. This was the beginning of some important work on increasing his self esteem.

\section{Emotional Reactions to Abuse}

Although the adolescents often differ widely in the types of abuse that they have experienced, they share common 
feelings and reactions to it. Certain issues arise repeatedly for most members.

\section{Avoidance}

Many admit that they try to avoid thinking about the abuse, although most report intrusive thoughts in spite of their efforts (Berliner \& Wheeler, 1987; Foley, 1987; Hazzard et al. 1986). The avoidance is adaptive in that it seems to allow them to concentrate and work in the school setting and to participate in social interactions and activities. Understandably, they are reluctant to give up this defense in the group and often complain that talking about the abuse only brings them further pain.

\section{Aloneness and Rejection}

Aloneness is another common theme (Bass \& Davis, 1988; Knittle \& Tuana, 1980; Lubell \& Soong, 1982). Many of the teens voice beliefs that no one could ever understand what they've been through. Along similar lines, they fear peer rejection. They share concerns that their peers will not believe them or will blame them for the abuse. Their self-esteem suffers and they feel damaged and/or "dirty." In the group setting the adolescents realize that they are not alone.

\section{Guilt and Shame}

Guilt and shame surrounding the abusive experience is expressed almost universally by the adolescents in the group (Browne \& Finkelhor, 1986; Rose, 1986). They feel they are to blame for the abuse in some way. They often believe that it was their "badness" or "stupidity" that caused the abuse. Senior members often take an active role in assuring new members that they are not to blame for the abuse. This also is an opportunity for the leaders to encourage discussion of ambivalent feelings that many victims experience. We discuss the fact that for some, pleasure may have been one of the myriad of reactions to the abuse, and that this pleasure does not mean that they caused the abuse to happen. We discuss how their bodies may respond with physical pleasure to sexual stimulation even at a time when they may be feeling anger or fear or repulsion. Some adolescents also have discussed how confusing it is when the perpetrator was caring and showing special interest in them. One girl talked about being abused by a neighbor who seemed "like a grandfather" to her. She enjoyed the special attention from him and talked of how difficult it is for her now to trust people who are nice to her.

\section{Helplessness}

Feelings of helplessness frequently are discussed (Knittle \& Tuana, 1980). One girl, in sharing for the third time some of the details of sexual abuse by a neighbor, began to reexperience emotionally the helplessness and panic she had felt. "He was so big, I couldn't push him off, he was crushing me-I was so little." She started to get in touch with the vulnerability and helplessness of the little girl who had been abused and began to forgive herself: "I really couldn't have done anything to stop him." Similarly, a boy who had experienced repetitive physical abuse at the hands of an alcoholic father talked of wanting to be like "Hulk Hogan" or "Superman" so that he could stop his father's attacks. Group members often practice assertiveness skills to overcome feelings of helplessness. They sometimes rehearse what they might say in everyday confrontations with peers and/or family members. And some work specifically on what they would like to say to their perpetrators. One girl's father was in prison. He had abused her physically and sexually. She wrote a letter to him, which she shared with the group, confronting him with his actions. Whether or not she mailed the letter is unknown. But the act of asserting herself in the group setting served to validate her own self-worth and to alleviate some of her helpless feelings.

\section{Distrust and Anger}

Also common are feelings of distrust (Browne \& Finkelhor, 1986; Rose, 1986). The teens describe tremendous difficulties in trusting others. Many have been betrayed by family members or people in positions of authority. Those who should have been trustworthy were not. The work of trusting again is initiated in the safe group environment.

Finally, the adolescents experience and verbalize their anger-anger at the perpetrator and anger at other adults who did not protect them (Bass \& Davis, 1988; Berliner \& Wheeler, 1987; Browne \& Finkelhor, 1986). In the group setting, their anger is heard and validated by their peers. Some teens talk of their desire to confront family members and gain support and courage from peers to follow through in family sessions. It has been our experience that this anger often is directed inward in a self-destructive manner (Bass \& Davis, 1988; Browne \& Finkelhor, 1986). Within the group, we identify how scratching, punching walls, running away, and drug use, are means of continuing the abuse. Ways of redirecting this anger in a healthier manner are explored and encouraged in the group.

\section{Conclusion}

It seems that along with the increased media and professional attention to childhood abuse in our country, there has been an increased willingness on the part of victims to reveal their abusive experiences. The opportunity for victims to participate in a support group addresses this need. The heterogeneous nature of the group does not seem to impede the group work, but in many ways to enhance it.

The adolescents formed a cohesive group based on common feelings and concerns related to the abuse. Exploration 
of these feelings with their peers in a group setting helps to decrease feelings of isolation, helplessness, and guilt while increasing self-esteem (Herman, 1981). The work that these adolescents do can be very painful and frightening. It is essential, therefore, that the group leaders be empathic and sensitive and they communicate these qualities effectively to the adolescents. The leaders must be knowledgeable and comfortable with the issue of abuse. And, the group atmosphere must be one of respect, acceptance, and safety. In an inpatient setting, frequent communication with other disciplines also is necessary. The work done in the safe group often compliments work in individual and family therapy.

This experience suggests that, given the opportinity of a support group, abused teens will courageously face their fears and pain and grow healthier as a result.

\section{References}

Bass, E., \& Davis, L. (1988). The courage to heal. New York: Harper and Row.
Berliner, L., \& Wheeler, J. R. (1987). Treating the effects of sexual abuse on children. Journal of Interpersonal Violence, 2(4), 415-434.

Browne, A., \& Finkelhor, D. (1986). Initial and long-term effects: A review of the research. In D. Finkelhor (Ed.), A sourcebook on child sexual abuse (pp. 143-180). Beverly Hills, CA: Sage.

Foley, T. S. (1987, Fall). He messed with my mind so he could mess with my body. Creighton University Window, pp. 14-20.

Hazzard, A., King, H. E., \& Webb, C. (1986). Group therapy with sexually abused adolescents. American Journal of Psychotherapy. XL(2), 213-223.

Herman, J. L. (1981). Father-daughter incest. Cambridge, MA: Harvard University Press.

Knittle, B. J., \& Tuana, S. J. (1980). Group therapy as primary treatment for adolescent victims of intrafamilial sexual abuse. Clinical Social Work Journal, 8(4), 236-242.

Lubell, D., \& Soong, W. (1982). Group therapy with sexually abused adolescents. Canadian Journal of Psychiatry, 27, 311-315.

Rose, D. S. (1986). "Worse than death": Psychodynamics of rape victims and the need for psychotherapy. American Journal of Psychiatry, 143(7), 817-824.

Straus, M. A., Gelles, R. J., \& Steinmetz, S. K. (1980). Behind closed doors: Violence in the American family. Garden City, NY: Anchor Press/Doubleday.

Yalom, I. D. (1985). The theory and practice of group therapy (3rd ed.). New York: Basic Books.

\section{Conference Calendar}

Public Sector Psychosocial Nursing in Institutions: Formulating the Subspecialty. May 16-19, 1990, Seattle, WA. Contact Continuing Nursing Education, University of Washington, SC-72, Seattle, WA 98195. (206) 543-1047.

Third Annual National Conference on Child Abuse: Clinical Issues and Controversies. April 13-15, 1990, New Orleans, LA. For information contact Resource Applications, Inc., 7250 Parkway Drive, Hanover, MD 21076. (800) 826-1877, (301) 7969010.

Notices of regional and national conferences of interest to JCPN readers will be published without cost. Submit conference information at least 6 months in advance of desired publication date.
Advocates for Child Psychiatric Nursing, Inc., National Conference. September 13-15, 1990, Atlanta, GA. Sponsored by Advocates for Child Psychiatric Nursing, Inc., Grady Memorial Hospital, and Georgia State University. Contact Beatrice Crofts Yorker, JD, RN, Department Chair and Assistant Professor, Psychiatric Mental Health Nursing, School of Nursing, Georgia State University, University Plaza, Atlanta, GA 30303. (404) 651-3044. 